\title{
Intravital microscopy
}
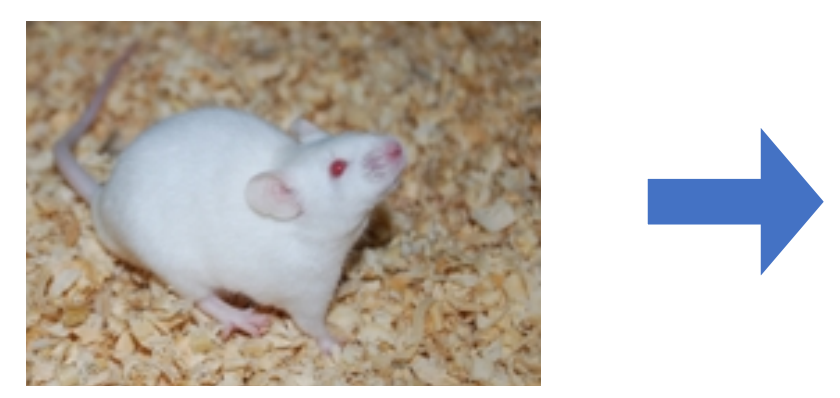

Male Wistar rats

(140-220g)

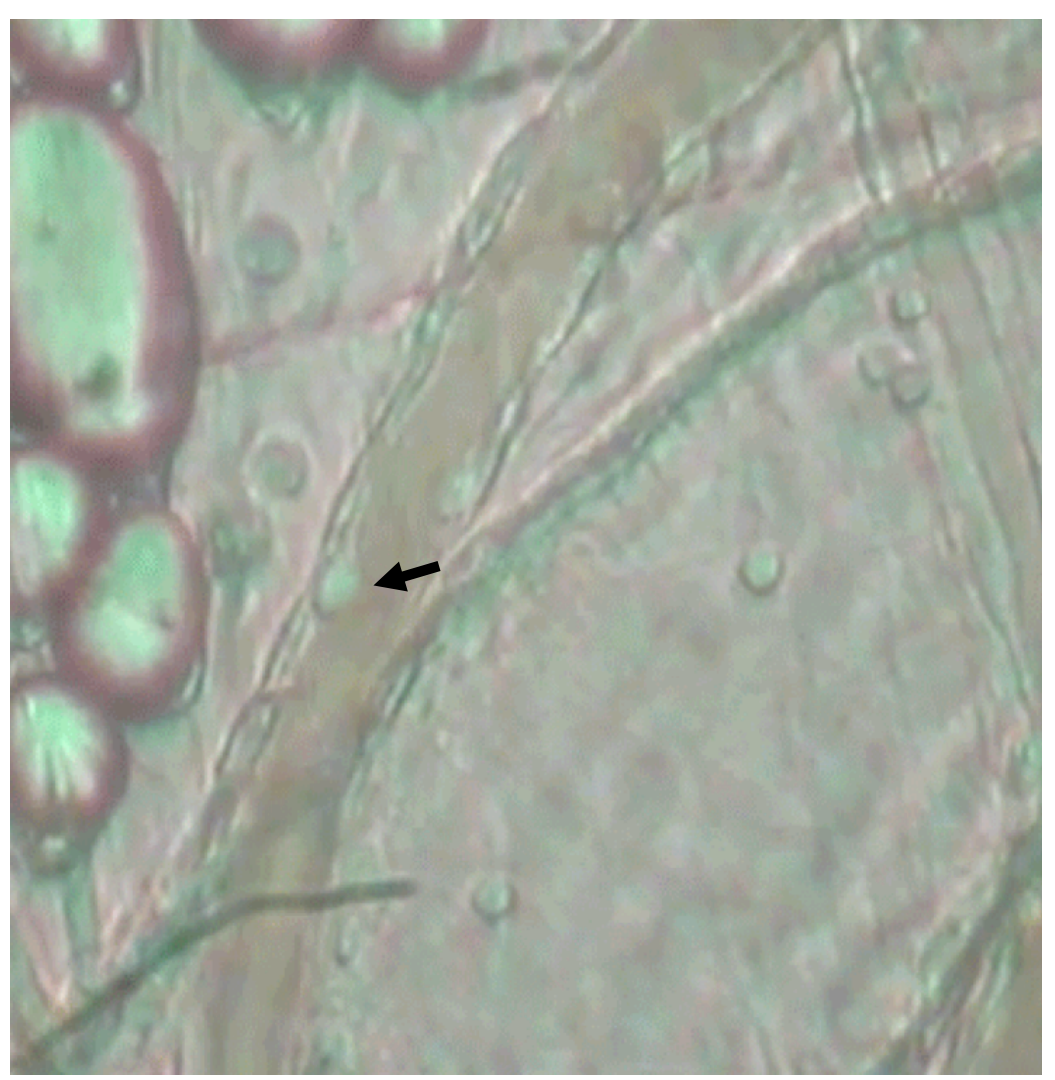

Visualization and analysis of leukocytes. Postcapillary venules with diameters ranging from 18-25 $\mu \mathrm{m}$. Arrow - leukocyte in rolling.

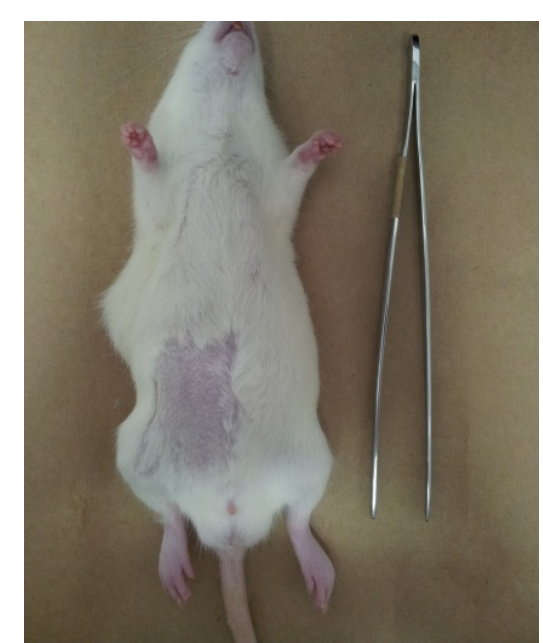

Trichotomy

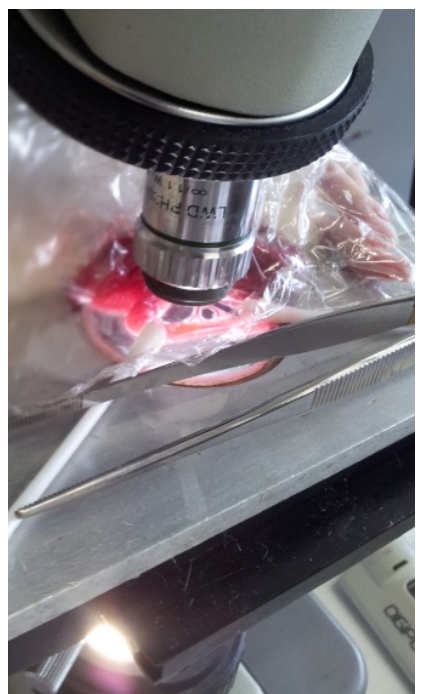

Ileal mesentery exteriorized. The mesenteric exposed for observation of the microcirculation vessels. The preparation was kept moist and warm by irrigation with Ringer-Locke solution $\left(37^{\circ} \mathrm{C}, \mathrm{pH} 7.2\right.$ - 7.4)

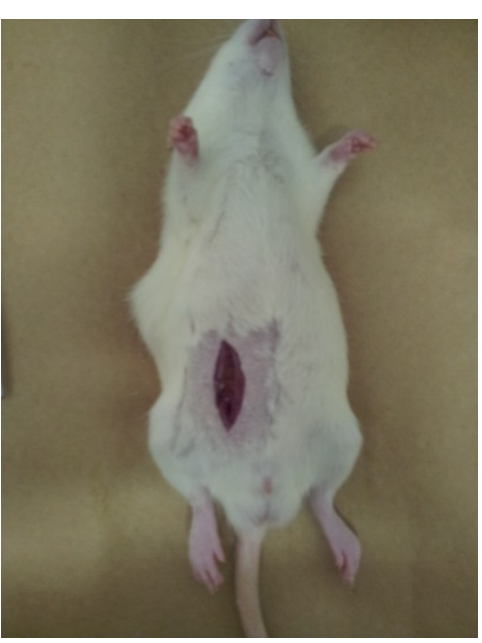

Abdominal incision

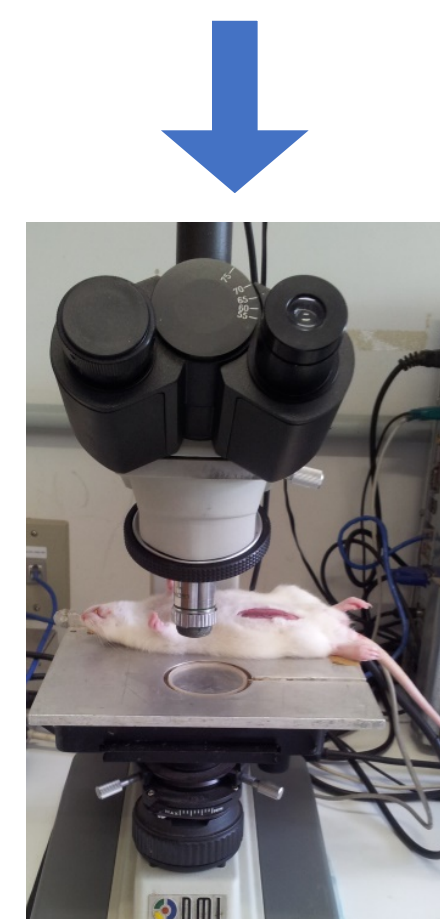

Adaptation on heated plate $\left(37^{\circ} \mathrm{C}\right)$ for $5 \mathrm{~min}$ 